\begin{tabular}{|c|l|}
\hline Title & $\begin{array}{l}\text { A rsenic contamination of groundwater in Nawabganj, Bangladesh, focusing on the relationship with other metals and } \\
\text { ions. }\end{array}$ \\
\hline Author(s) & Ohno, K.; Furukawa, A.; Hay ashi, K.; Kamei, T.; Magara, Y. \\
\hline Citation & Science and Technology, 52(8), 87-94 \\
\hline Issue Date & 2005 \\
\hline Doc URL & http://hdl.handle.net/2115/14657 \\
\hline Type & article (author version) \\
\hline File Information & WST 2005-52-8.pdf \\
\hline
\end{tabular}

Instructions for use 


\title{
Arsenic Contamination of Groundwater in Nawabganj, Bangladesh, Focusing on the Relationship with Other Metals and lons
}

\author{
K. Ohno*, A. Furukawa*, K. Hayashi*, T. Kamei* and Y. Magara* \\ * Department of Urban and Environmental Engineering, Hokkaido University, N13, W8, \\ Kita-ku, Sapporo, 060-8628, Japan
}

\begin{abstract}
Serious arsenic contamination of groundwater in Bangladesh has been frequently reported and of great concern. In this research, repeated water sampling from the same 10 tubewells in Nawabganj municipality, Bangladesh had been conducted and analysed, focusing on the seasonal variation of water quality and the relationship among arsenic and other metals and ions. With respect to the seasonal variation of water quality, arsenic and iron concentrations were higher in the rainy season in general although the tendency was not consistent and it depended on the tubewell and the time. Correlation between arsenic and iron could not be observed in this study ( $r=-0.01)$ when using all cases. It is because no correlation was observed in higher arsenic concentration range. Arsenic removal by means of co-precipitation with coexisting iron is known as one of the locally applicable techniques in Bangladesh, but the result from this study suggests that some additional treatments such as the extra injection of iron should be performed in some cases, especially the cases where the arsenic concentration is high. Correlation between arsenic and other substances were also analysed. As a result, manganese $(r=0.37)$, molybdenum $(r=0.33)$ and sulfate ion $(r=-0.33)$ significantly correlated with arsenic $(p<0.05)$. The negative correlation between arsenic and sulfate ion implies the dissolution of arsenic into groundwater under the reductive condition although there are some exceptional cases.
\end{abstract}

Keywords arsenic, Bangladesh, groundwater contamination, iron, manganese, sulfate

\section{Introduction}

In 1970s, infectious disease was widespread and the mortality rate of infants and children was very high in Bangladesh because pathogenic microbes contaminated surface water, which had been drunk directly by the people. In order to overcome this problem, millions of shallow tubewells have been installed. As a consequence, the mortality rate of infants and children has greatly decreased for these 30 years (Curry et al., 2000). But since the late 1980 s, it has been known that shallow tubewell water is contaminated by naturally originated arsenic, in many parts of Bangladesh and West Bengal of India (Chakraborty and Saha, 1987). Nowadays, arsenic contamination in Bangladesh is said to be the severest in the world and patients of skin disease caused by arsenic have been detected (Karim, 2000). It has been estimated that, for instance, about 35 million people in Bangladesh are affected by arsenic contamination (Ahmed et al., 1997).

Although serious arsenic contamination of groundwater in Bangladesh has been frequently reported as mentioned above, there are not many articles that refer to the relationship between arsenic and other substances and the seasonal variation of groundwater 
quality. In this paper, a series of tubewell surveys was conducted in Nawabganj municipality, Bangladesh, focusing on the seasonal variation of groundwater quality because Bangladesh has distinguishable two seasons, rainy season and dry season. Furthermore, concentrations of other metals and ions were determined and compared with that of arsenic to explore the mechanism of arsenic contamination in groundwater in Nawabganj district.

\section{Materials and methods}

\section{Sample collection}

Tubewell water sample collection had been done 8 times from November 2000 to August 2003 , in the central part of Nawabganj municipality (latitude N24 $34^{\prime}-37^{\prime}$, longitude E88 14'-17') in Nawabganj District which is located on the west end of Bangladesh. Tubewell water sampling locations are shown in Figure 1. Population in Nawabganj municipality is about 150,000 (Bangladesh Bureau of Statistics, 2001) and there is only a little farmland near the sampling points. Water samples had been collected from the same 10 shallow tubewells to investigate the seasonal fluctuation of arsenic and other metals. These 10 tubewells were selected from the different sub-divisions of the municipality by the consultation with local engineers. In the consultation, the engineers were asked to select the tubewells that were the representatives of the arsenic contamination situation in each sub-division, but it was not considered whether people drank the tubewell water or not. Therefore, the result does not directly indicate the intake rate by the local people although some of the arsenic contaminated tubewell water was drunk.

Apart from the repeated water collection of 10 tubewells, other tubewells and dug wells and river waters were collected sporadically. Results of analyses of the tubewell water were included in the data set for the statistical analyses for comparison, but those of dug well and river waters were not included because the water quality is thought to be totally different from tubewell water.

Every water sample was divided in three portions, for the analysis of metals (including total arsenic (total-As)), of trivalent arsenic (As (III)) and of ions. The portion for the
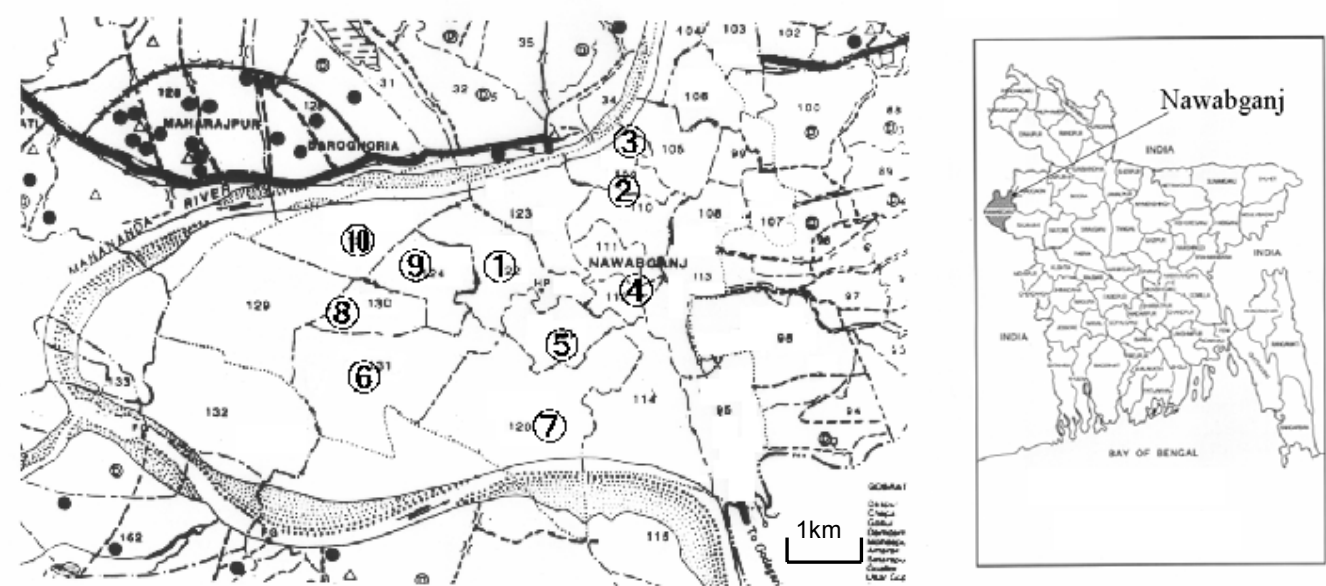

Figure 1. Water sampling locations. 
analysis of metals was adjusted its $\mathrm{pH}$ to below 1 by addition of nitric acid (analytical grade free from heavy metals, Wako Pure Chemical Industries, Ltd., Osaka, Japan) to prevent adsorption to the bottle, and the portion of As (III) was also done so by sulfuric acid (analytical reagent grade free from arsenic, Wako, Osaka, Japan) to prevent oxidation of trivalent arsenic to pentavalent arsenic (As (V)). The portion for ions was filtered using $0.45 \mu \mathrm{m}$ pore size membrane filter (DISMIC-25AS-045AN, Advantec, Tokyo, Japan) to remove suspended matter. All sampling bottles were carried in dark containers and stored in cool condition until analysed.

\section{Analytical methods}

Water temperature, $\mathrm{pH}$, Dissolved Oxygen (DO) and Electric Conductivity (EC) were measured on site using potable analysers (D-21/OM-12/ES-12, Horiba, Japan). Concentrations of dissolved organic carbon (DOC) were determined by a TOC analyser (TOC-5000A, Shimadzu, Japan). UV absorbance at 260nm (E260) was measured by a spectrophotometer (DR-4000, HACH, USA). Concentrations of metals (As, Al, Mn, Fe, Ni, $\mathrm{Cu}, \mathrm{Zn}, \mathrm{Se}, \mathrm{Cr}, \mathrm{Mo}, \mathrm{Cd}, \mathrm{Sb}, \mathrm{Pb}$ and $\mathrm{U}$ ) were determined by ICP/MS (HP-4500, Agilent, USA). Concentrations of As (III) were determined by Hydride Generation-ICP/AES (HVG-1 and ICPS-7500, Shimadzu, Japan). Concentrations of anions $\left(\mathrm{Cl}^{-}, \mathrm{Br}^{-}, \mathrm{NO}_{2}{ }^{-}, \mathrm{NO}_{3}{ }^{-}\right.$and $\left.\mathrm{SO}_{4}{ }^{2-}\right)$ and cation $\left(\mathrm{NH}_{4}^{+}\right)$were determined by Ion Chromatography (DX-120, Dionex, USA) using the columns "Ion Pac AS12A" (Dionex, USA) for anions and "Ion Pac CS3" (Dionex, USA) for cation.

\section{Results and discussion}

\section{Concentrations of arsenic and other substances}

The results of water quality analysis of the 10 tubewells are summarized in Table 1 . Geometric mean concentration of arsenic was $0.15 \mathrm{mg} / \mathrm{L}$, ranging from 0.014 to $2.63 \mathrm{mg} / \mathrm{L}$, as of the samples collected in April 2002. Arsenic concentration of all 10 tubewells exceeded WHO Guideline for Drinking Water Quality (GDWQ) value, which is $0.01 \mathrm{mg} / \mathrm{L}$, and 7 tubewells exceeded Bangladeshi domestic water quality standard $(0.05 \mathrm{mg} / \mathrm{L})$. Although these waters were collected from rather arsenic contaminated tubewells as mentioned above,

Table 1. Results of tubewell water quality analysis collected in April 2002.

\begin{tabular}{|c|c|c|c|c|c|c|c|c|c|c|c|c|c|c|}
\hline No. & $\begin{array}{c}\text { As } \\
\mu \mathrm{g} / \mathrm{L}\end{array}$ & $\begin{array}{c}\text { Temp. } \\
{ }^{\circ} \mathrm{C} \\
\end{array}$ & $\mathrm{pH}$ & $\begin{array}{r}\mathrm{DO} \\
\mathrm{mg} / \mathrm{L}\end{array}$ & $\begin{array}{c}\mathrm{EC} \\
\mathrm{mS} / \mathrm{cm}\end{array}$ & $\begin{array}{c}\text { E260 } \\
1 / \mathrm{cm} \\
\end{array}$ & $\begin{array}{l}\mathrm{DOC} \\
\mathrm{mg} / \mathrm{L}\end{array}$ & $\begin{array}{c}\mathrm{Al} \\
\mathrm{mg} / \mathrm{L}\end{array}$ & $\begin{array}{c}\mathrm{Mn} \\
\mathrm{mg} / \mathrm{L}\end{array}$ & $\begin{array}{c}\mathrm{Fe} \\
\mathrm{mg} / \mathrm{L}\end{array}$ & $\begin{array}{c}U \\
\mu \mathrm{g} / \mathrm{L} \\
\end{array}$ & \begin{tabular}{|c}
$\mathrm{NO}_{2}{ }^{-}+\mathrm{NO}_{3}{ }^{-}$ \\
$\mathrm{mg}-\mathrm{N} / \mathrm{L}$
\end{tabular} & $\begin{array}{c}\mathrm{NH}_{4}{ }^{+} \\
\mathrm{mg}-\mathrm{N} / \mathrm{L} \\
\end{array}$ & $\begin{array}{c}\mathrm{SO}_{4}{ }^{2-} \\
\mathrm{mg} / \mathrm{L} \\
\end{array}$ \\
\hline 1 & 94 & 26.6 & 7.2 & 2.0 & 0.7 & 0.012 & 0.9 & nd & 0.2 & 2.7 & $\overline{n d}$ & 0.3 & 0.6 & 0.7 \\
\hline 2 & 14 & 27.1 & 7.2 & 1.7 & 1.0 & 0.005 & 0.7 & nd & 1.0 & 0.9 & 3.9 & 0.2 & 0.2 & 34.9 \\
\hline 3 & 15 & 27.5 & 7.5 & 5.8 & 0.8 & 0.008 & 1.0 & nd & 0.6 & 0.6 & 1.2 & 0.2 & 0.2 & 19.5 \\
\hline 4 & 510 & 27.0 & 7.1 & 2.1 & 0.8 & 0.024 & 1.1 & nd & 1.4 & 6.7 & nd & nd & 1.8 & 0.4 \\
\hline 5 & 80 & 27.1 & 7.1 & 2.7 & 0.7 & 0.008 & 0.7 & 0.13 & 0.9 & 8.4 & nd & 0.2 & 0.7 & 1.0 \\
\hline 6 & 2630 & 27.1 & 7.3 & 2.0 & 0.9 & 0.039 & 1.8 & nd & 1.2 & 1.1 & 0.2 & 0.2 & 1.9 & 0.6 \\
\hline 7 & 520 & 26.9 & 7.4 & 1.9 & 0.8 & 0.028 & 1.4 & nd & 0.7 & 0.3 & 0.4 & 0.4 & 1.1 & 0.8 \\
\hline 8 & 420 & 27.1 & 7.2 & 2.1 & 0.9 & 0.027 & 1.4 & nd & 1.3 & 1.8 & 0.2 & 0.2 & 1.6 & 0.8 \\
\hline 9 & 450 & 27.0 & 7.1 & 1.9 & 0.9 & 0.201 & 7.1 & nd & 0.6 & 11.2 & nd & 0.2 & 10.9 & 0.6 \\
\hline 10 & 24 & 27.2 & 7.1 & 2.1 & 0.7 & 0.014 & 0.7 & nd & 0.9 & 1.3 & 0.5 & 0.3 & 0.7 & 0.7 \\
\hline
\end{tabular}


this result may indicate that arsenic contamination is very severe in the central Nawabganj municipality. Seeing Figure 1, waters from sampling points \#2, \#3 and \#10 which are near the river contain less arsenic in terms of geographic aspect. River water may infiltrate into groundwater nearby. Comparing arsenic concentrations with that of nitrite and nitrate ions, of ammonium ion and of sulfate ion implies that arsenic dissolution to groundwater is mainly occurred under reductive condition.

Apart from arsenic, concentrations of iron and manganese were above the WHO GDWQ values, which are 0.3 and $0.1 \mathrm{mg} / \mathrm{L}$ respectively although they are not the health-based guideline values. In one tubewell and some dug wells which were collected sporadically, uranium over the WHO GDWQ value $(2 \mu \mathrm{g} / \mathrm{L}$, provisional) was detected. With respect to other measured hazardous metals, their concentrations in groundwater were all below WHO GDWQ value. River water did not contain any hazardous metals that exceeded WHO GDWQ values.

\section{Seasonal variation}

Time course change in concentrations of arsenic and iron is shown in Figure 2. Both concentrations were higher in the rainy season than in the dry season in the year 2001. But in the case of the year 2003, seasonal changes did not have the clear effect. According to the other researches, Tanabe et al. (2001) supported the increase in arsenic concentration in the rainy season. On the other hand, results by Tareq et al. (2003) did not show the clear difference in arsenic concentration by seasonal changes. Returning to the Figure 2, seasonal variations in arsenic and iron concentrations were not consistent. One plausible explanation for this inconsistency is the differences among the properties of the tubewells such as surrounding soil condition including adsorbed arsenic and iron concentrations and groundwater level, and it should be further investigated.

In spite of this inconsistency, some trends can be seen from Figure 2. One is that the larger increase in arsenic and iron concentrations in the rainy season can be observed in the tubewell waters that contain higher arsenic and iron in the dry season. Another is that the tubewells that show the bigger difference in arsenic concentration between seasons are
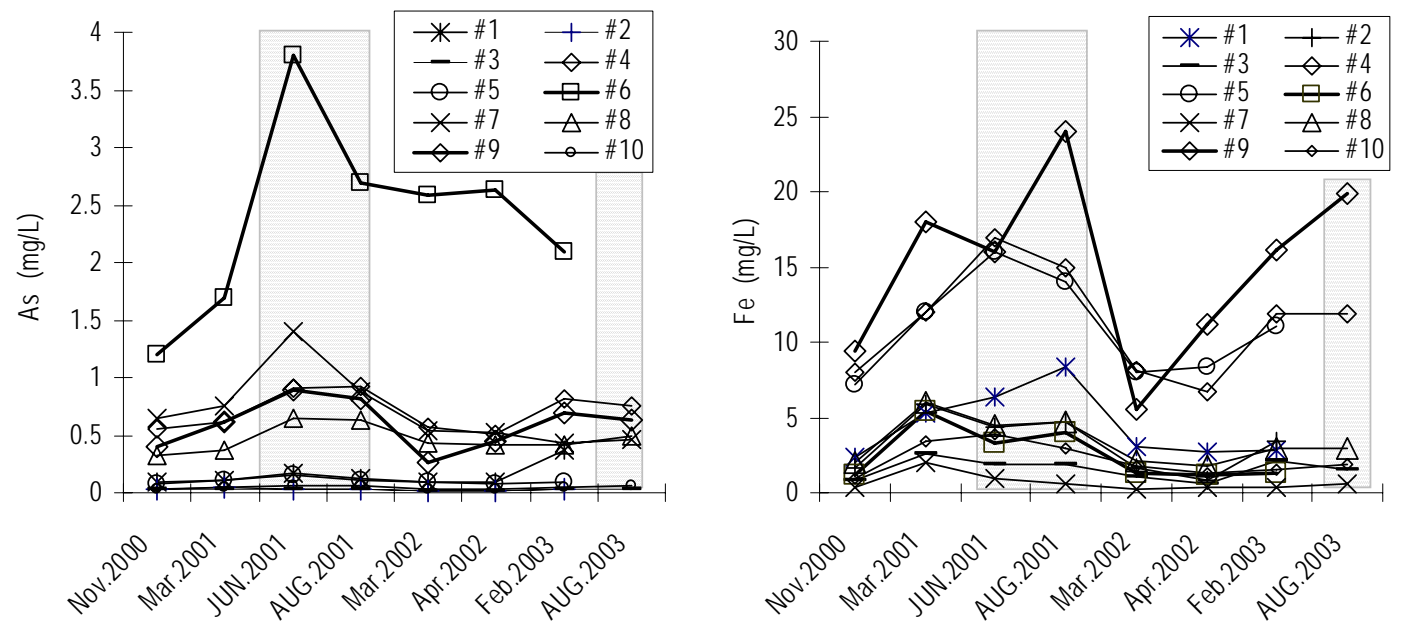

Figure 2. Time course change in concentrations of arsenic (left) and iron (right).

(Darkened part indicates the rainy season) 
different from the tubewells with big differences in iron concentration. These trends imply that arsenic and iron concentrations become unstable in the rainy season and that the dissolution of arsenic and iron into groundwater does not always coincide.

\section{Ratio of As (III) to total-As}

Figure 3 shows the relationship between (As (III)/ total-As) and total-As. The ratio of As (III) increases with increase of total-As concentration. It is possible that As (III) was oxidized to As (V), especially in the lower range in arsenic concentration, during the water sampling owing to the aeration in pumping tubewells. Therefore, the real ratio of As (III) should be higher than that shown in Figure 3. These results also suggest that arsenic dissolution occurs mainly under reductive condition.

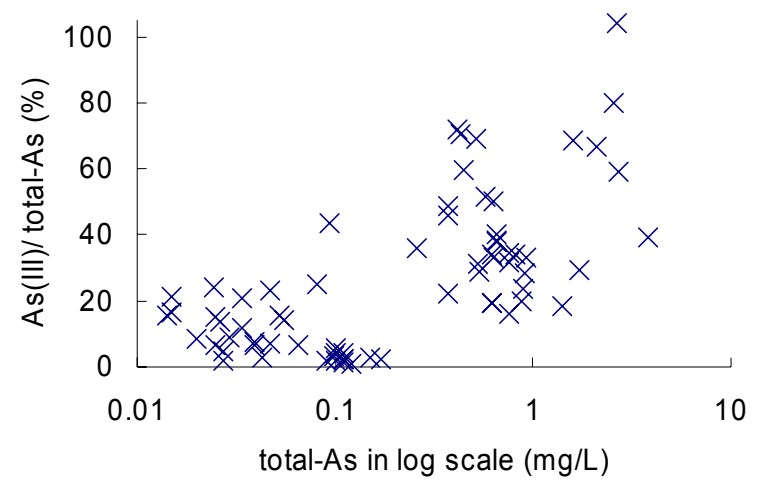

Figure 3. (As (III) / total-As) versus total-As in log scale.

\section{Relationship between arsenic and other substances}

\section{Coexistence of arsenic and iron in groundwater}

Relationship between arsenic and iron concentrations is shown in Figure 4. Relatively good correlation was observed by Nickson et al. (2000), Berg et al. (2001) and so on. But in this study, no correlation can be observed when considering all data. It is mainly because of the cases with high arsenic but low iron concentrations (cases inside the ellipse " $\mathrm{B}$ " in Figure 4).

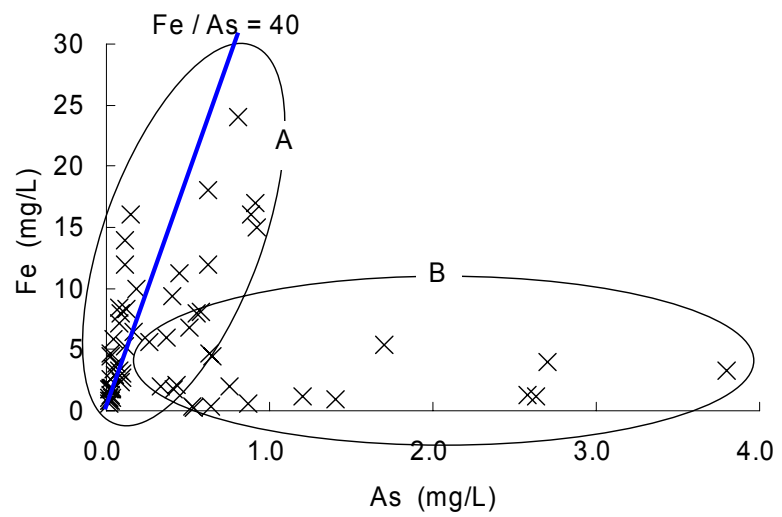

Figure 4. Iron versus arsenic (solid line does not represent regression line but "Fe / As = 40"). 
The reason why these cases appear will be discussed later. Good correlation can be observed if the data only inside the ellipse " $A$ " in Figure 4 are used.

In Bangladesh, arsenic removal in groundwater by means of co-precipitation with coexisting iron is known as one of the effective techniques. There are various types of arsenic removal setups using this technique and they are equipped in a house and installed as a community based arsenic removal plant. Simazaki et al. (2001) investigated the setups and found that some of them did not work properly, that is, arsenic removal was poor. One explanation for this poor performance is that the iron/arsenic (Fe/As) ratio is lower than required. Meng et al. (2001) suggested that $\mathrm{Fe} / \mathrm{As}$ ratio should be greater than 40 to obtain $85 \%$ of arsenic removal in the case of typical groundwater in Bangladesh, which contains $1.9 \mathrm{mg}-\mathrm{P} / \mathrm{L}$ of phosphate and $18 \mathrm{mg}-\mathrm{Si} / \mathrm{L}$ of silicate. As seen in Figure 4, about half of the cases do not satisfy this requirement, although concentrations of phosphate and silicate, which interfere the arsenic removal (Meng et al., 2001), were not measured in this study. The addition of iron, or a kind of coagulants, should be performed when Fe/As ratio is not enough in raw water.

\section{Correlation between arsenic and other substances}

Correlation matrix was calculated in order to search the relationship between arsenic and other substances in addition to iron. Table 2 summarizes the results. As mentioned above, significant correlation does not seen between arsenic and iron $(\mathrm{r}=-0.01)$. Substances that show the significant correlation $(\mathrm{p}<0.05)$ with arsenic are manganese $(\mathrm{r}=0.37)$, molybdenum $(\mathrm{r}=0.33)$ and sulfate ion $(\mathrm{r}=-0.33)$. In order to visualize the relationship among arsenic, sulfate ion, iron and manganese, the matrix of scatter plots was drawn as seen in Figure 5. Here, molybdenum was excluded because of its very low concentrations $(0.0034 \mathrm{mg} / \mathrm{L}$ in average) although it shows good correlation with arsenic.

As discussed above and seen in Figure 4, there are the cases with high arsenic and low iron concentration. Looking into the upper right block in Figure 5, which shows the relationship between arsenic and manganese, manganese concentration is relatively high in these cases. Good correlation between arsenic and manganese in addition to arsenic and iron was observed in fine particle part of sediment core samples by Anawar et al. (2003). Accordingly, it is possible that arsenic is eluted into groundwater with manganese when iron is scarce in geological layer.

Table 2. Correlation matrix

\begin{tabular}{|c|c|c|c|c|c|c|c|c|c|c|c|c|}
\hline & $\begin{array}{l}\text { As } \\
59 \\
\end{array}$ & $\begin{array}{l}\mathrm{Zn} \\
46 \\
\end{array}$ & $\begin{array}{c}\mathrm{Mn} \\
58 \\
\end{array}$ & $\begin{array}{l}\mathrm{Fe} \\
58 \\
\end{array}$ & $\begin{array}{l}\mathrm{Al} \\
28 \\
\end{array}$ & $\begin{array}{l}\mathrm{Ni} \\
41 \\
\end{array}$ & $\begin{array}{l}\mathrm{Cu} \\
46 \\
\end{array}$ & $\begin{array}{l}\mathrm{Se} \\
44 \\
\end{array}$ & $\begin{array}{l}\text { Mo } \\
44 \\
\end{array}$ & $\begin{array}{l}\mathrm{Cl}^{-} \\
59 \\
\end{array}$ & $\begin{array}{c}\mathrm{SO}_{4}{ }^{2-} \\
46 \\
\end{array}$ & $\begin{array}{l}\text { EC } \\
59 \\
\end{array}$ \\
\hline As & 1 & & & & & & & & & & & \\
\hline $\mathrm{Zn}$ & -0.26 & 1 & & & & & & & & & & \\
\hline $\mathrm{Mn}$ & 0.37 & -0.40 & 1 & & & & & & & & & \\
\hline $\mathrm{Fe}$ & $-\overline{0.01}$ & -0.13 & 0.13 & 1 & & & & & & & & \\
\hline Al & -0.14 & -0.12 & 0.03 & 0.09 & 1 & & & & & & & \\
\hline $\mathrm{Ni}$ & -0.04 & 0.32 & -0.09 & 0.15 & -0.37 & 1 & & & & & & \\
\hline $\mathrm{Cu}$ & 0.00 & 0.22 & -0.09 & 0.23 & -0.31 & 0.84 & 1 & & & & & \\
\hline $\mathrm{Se}$ & -0.06 & 0.16 & -0.03 & -0.03 & -0.60 & $\overline{\underline{0.51}}$ & $\underline{0.32}$ & 1 & & & & \\
\hline Mo & $\underline{0.33}$ & -0.14 & 0.13 & -0.26 & -0.15 & -0.10 & -0.18 & -0.01 & 1 & & & \\
\hline $\mathrm{Cl}^{-}$ & $-\overline{0.14}$ & 0.20 & 0.19 & -0.04 & -0.17 & 0.15 & $\underline{0.30}$ & 0.36 & -0.26 & 1 & & \\
\hline $\mathrm{SO}_{4}{ }_{4-}^{2-}$ & -0.33 & 0.11 & 0.02 & -0.31 & -0.17 & 0.09 & 0.24 & 0.31 & -0.28 & $\underline{0.84}$ & 1 & \\
\hline EC & 0.05 & 0.22 & -0.11 & 0.10 & -0.13 & 0.16 & 0.05 & 0.32 & -0.08 & $\underline{0.33}$ & 0.08 & 1 \\
\hline \multicolumn{13}{|c|}{ Number $p<.01$} \\
\hline
\end{tabular}




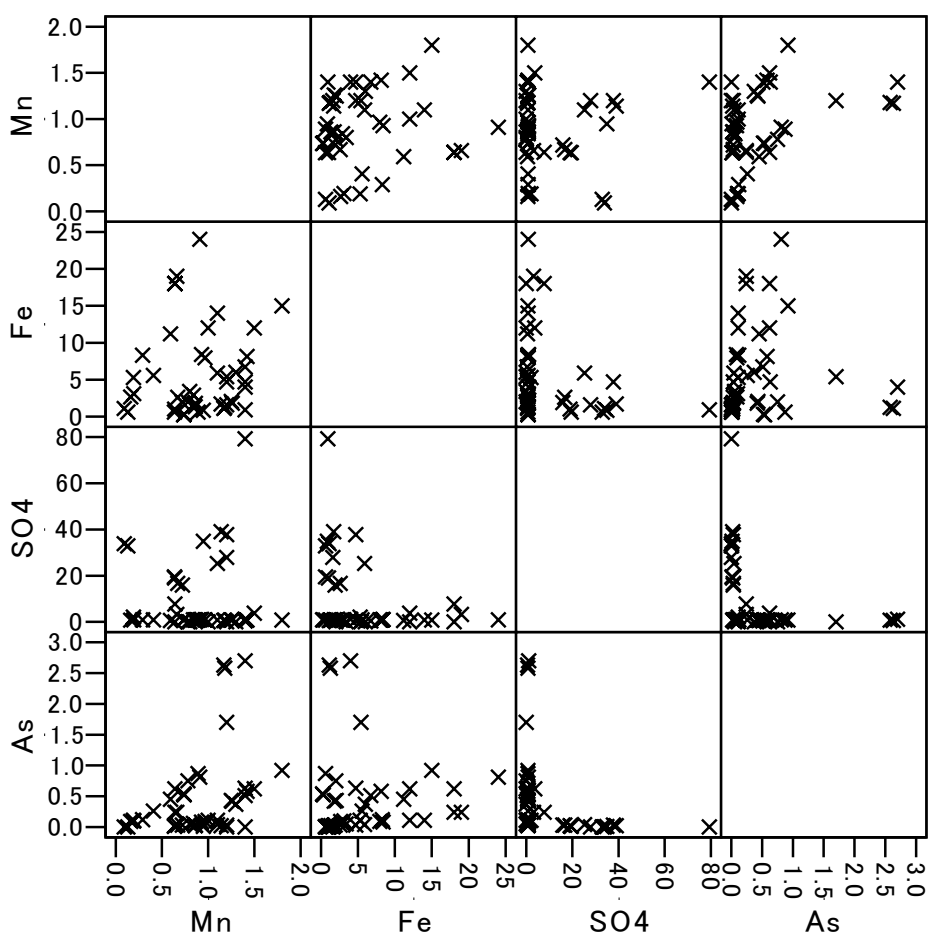

Figure 5. Scatterplot matrix (unit: $\mathrm{mg} / \mathrm{L}$ )

Turning now to the relationship between sulfate ion and other substances, which can be seen in the $3^{\text {rd }}$ column in Figure 5, sulfate ion is clearly in inverse proportion to arsenic. This tendency also supports that arsenic contamination in groundwater mainly occurs under reductive condition. There are some exceptional cases that high arsenic $(0.5 \mathrm{mg} / \mathrm{L})$ and sulfate ion $(10 \mathrm{mg} / \mathrm{L})$ concentrations are observed (Anawar et al., 2003) although there is not a clear exception in this study. One plausible explanation of these exceptions is that the existence of arsenic-rich geological layer very near the strainers of a tubewell, and arsenic contamination could occur even under oxidative condition in such cases.

With respect to the relationship between sulfate ion and manganese, high manganese concentration can be observed regardless of sulfate ion concentrations. Furthermore, no correlation between them $(\mathrm{r}=0.02)$ is observed as seen in Table 2. This makes the relationship among arsenic, iron, manganese and sulfate ion more complicated and should be further investigated.

\section{Conclusion}

As the results of repeated sampling and analyses of the same 10 tubewells, the followings are obtained. Firstly, not only concentration of arsenic but also of iron and manganese exceeded WHO Guideline value of Drinking Water Guideline. Secondly, arsenic and iron concentrations were, in general, higher in the rainy season in terms of seasonal variations although the tendency was not consistent and it depended on the tubewell and the year. Thirdly, no correlation could be observed between arsenic and iron when considering all data. It is because no correlation was observed in higher arsenic concentration range. Arsenic 
removal by co-precipitation with coexisting iron is known to be one of the locally applicable techniques in Bangladesh, but this result suggests that some additional treatments should be performed in some cases. Fourthly, manganese and sulfate ion correlated with arsenic and these two substances in addition to iron seems to be the key substances to reveal the mechanism of arsenic contamination in groundwater. Lastly, according to the results and statistical analyses, it may be reasonable to conclude that arsenic contamination in groundwater mainly occurs under reductive condition in Nawabganj municipality although there are some exceptional cases.

\section{Acknowledgement}

The authors are grateful to Prof. Md. Hamidur Rahman (Rajshahi University, Bangladesh) for his kind collaboration in their field survey.

\section{References}

Ahmad, S.A., Bandarnayake, D., Khan, A.W., Hadi, S.A., Uddin, G. and Halim, M.A. (1997) Arsenic in ground water and arsenicosis in Bangladesh, Int. J. Environ. Health Res., 7, 271-276

Anawar H.M., Akai, J., Komaki, K., Terao, H., Yoshioka, T., Ishizuka, T., Safiullah, S. and Kato, K. (2003) Geochemical occurrence of arsenic in groundwater of Bangladesh: sources and mobilization process, J. Geochem. Exploration, 77, 109-131

Bangladesh Bureau of Statistics (2001) Population Census 2001 Preliminary Report

Berg, M., Tran, H.C., Nguyen, T.C., Pham, H.V., Schertenleib, R. and Giger, W. (2001) Arsenic contamination of groundwater and drinking waiter in Vietnam: A human health threat, Environ. Sci. Tech., 35 (13), 2621-2626

Chakraborty, A. K. and Saha, K. C. (1987) Arsenical dermatiosis from tubewell water in West Bengal, Indian J. Med. Res., 85, 326-334

Curry, A., Carrin G., Bartram, J., Yamamura, S., Heijnen, H., Sims, J., Hueb, J. and Sato., Y. (2000) Towards an assessment of the socioeconomic impact of arsenic poisoning in Bangladesh, World Health Organization, WHO/SDE/WSH/00.4

Karim, M (2000) Arsenic in ground water and health problems in Bangladesh, Wat. Res., 34 (1), 304310

Meng, XG., Korfiatis, G.P., Christodoulatos, C., Bang, S. (2001) Treatment of arsenic in Bangladesh well water using a household co-precipitation and filtration system, Wat. Res., 35 (12), 2805-2810

Nickson, R.T., McArthur, J.M., Ravenscroft, P., Burgess, W.G. and Ahmed, K.M. (2000) Mechanism of arsenic release to groundwater, Bangladesh and West Bengal, Appl. Geochem., 15 (4), 403-413

Simazaki, D., Oh, J., Honda, R., Sugimura, M. and Yamamoto, K. (2001) Appropriate mitigation technologies for arsenic groundwater pollution in Bangladesh, Environ. Sci., 8 (5), 481-489

Tanabe, K., Yokota, H., Hironaka, H., Tsushima, S. and Kubota, Y. (2001) Arsenic pollution of groundwater in Bangladesh, Appl. Organometal. Chem., 15, 1-11

Tareq, S.M., Safiullah, S., Anawar H.M., Rahman, M.M. and Ishizuka, T. (2003) Arsenic pollution in groundwater: a self-organizing complex geocheminal process in the deltaic sedimentary environment, Bangladesh, Sci. Total Environ., 313 (1-3), 213-226 